\title{
QUALIDADE DE SEMENTES DE ARROZ IRRIGADO PRODUZIDAS COM DIFERENTES DOSES DE SILÍCIO ${ }^{1}$
}

\author{
ANTÔNIO RODRIGUES VIEIRA², JOÃO ALMIR OLIVEIRA ${ }^{3}$, RENATO MENDES GUIMARÃES ${ }^{3}$, \\ MARIA LAENE MOREIRA DE CARVALHO ${ }^{3}$, ELISE DE MATOS PEREIRA ${ }^{4}$, BRUNO OLIVEIRA CARVALHO ${ }^{4}$
}

\begin{abstract}
RESUMO - O arroz tem expressiva importância no cenário agrícola mundial, dada à extensão de áreas cultivadas e à sua produção. Sua importância e seu crescente consumo no mundo têm levado as instituições de pesquisa à busca cada vez maior por novas tecnologias que possam aumentar a produção de sementes de alta qualidade com um menor custo de produção. Assim, objetivou-se com este trabalho avaliar a influência da aplicação de diferentes doses de silicato de cálcio $\left(0,800,1600\right.$ e $\left.3200 \mathrm{~kg} \mathrm{ha}^{-1}\right)$ no plantio, sobre a qualidade fisiológica de sementes de arroz produzidas e armazenadas por 0,3 e 6 meses. Foram utilizadas sementes da cultivar Jequitibá, produzidas sob sistema irrigado por inundação, nos municípios de Lambari e Leopoldina - MG. Avaliaram-se o teor de água, germinação, vigor pelo envelhecimento acelerado, emergência e índice de velocidade de emergência e a atividade isoenzimática. $\mathrm{O}$ teor de água das sementes de $11,5 \%$ permaneceu inalterado durante o armazenamento. Em Lambari, local de solos com baixo teor de $\mathrm{Si}$, houve pequeno efeito favorável do silicato de cálcio aplicado, sobre a qualidade das sementes produzidas. Já em Leopoldina, local de solos com médio teor de $\mathrm{Si}$, a aplicação de silicato de cálcio foi prejudicial à qualidade das sementes produzidas.
\end{abstract}

Termos para indexação: Oryza sativa, silicato de cálcio, armazenamento, qualidade fisiológica, isoenzimas

\section{QUALITY OF IRRIGATED RICE SEEDS PRODUCED IN MINAS GERAIS STATE AND TREATED WITH DIFFERENT SILICON DOSAGES}

\begin{abstract}
Rice production is very important in world agriculture due to the area planted and production levels. It is produced and consumed in every continent and is considered the most important economic cereal in many developing countries. Its increasing consumption and status has lead to a growing interest by research institutions for new technologies to increase high quality seed production at lower costs. The objective of this research was to analyze the effect of different silicon dosages $\left(0,800,1600\right.$ and $\left.3200 \mathrm{~kg} \mathrm{~h}^{-1}\right)$ on the physiological quality of rice seeds after 0 , 3 and 6 months of storage. Seeds of the Jequitibá cultivar, produced in a flooded irrigation system in the municipalities of Lambari and Leopoldina, Minas Gerais state, were used. The moisture content, germination, vigor by accelerated aging test, emergence, rate of seed emergence (IVE) and the isoenzymatic activity were evaluated. The $11.5 \%$ mean moisture content of seed before storage remained unaltered during the entire storage period. In Lambari, where soils have low $\mathrm{Si}$, although the results are inconsistent, we observed a small positive effect of the calcium silicate
\end{abstract}

\footnotetext{
${ }^{1}$ Submetido em 25/03/2010. Aceito para publicação em 28/02/2011.

${ }^{2}$ Pesq. Dr. Empresa de Pesquisa Agropecuária de Minas Gerais/Unidade Regional EPAMIG Sul de Minas, Bolsista FAPEMIG, 37.200-000 Lavras - MG. E-mail: arvieira@epamig.ufla.br;
}

${ }^{3}$ Prof. Dr. Universidade Federal de Lavras, 37.200-000 - Lavras - MG.
E-mail: jalmir@dag.ufla.br; mlaenemc@dag.ufla.br; renatomg@dag. ufla.br.

${ }^{4}$ Estudantes de Pós-Graduação, Depto. de Fitotecnia, Universidade Federal de Lavras, 37.200-000 - Lavras - MG. E-mail: elisedematos@ yahoo.com.br; brunoagroufla@hotmail.com 
applied on seed quality. However, in Leopoldina, where local soils had medium contents of $\mathrm{Si}$, the application of calcium silicate was detrimental to seed quality.

Index terms: Oryza sativa, physiological quality, isoenzymes.

\section{INTRODUÇÃO}

O arroz é uma cultura adaptada a diferentes condições de solo e clima, com grãos de excelente balanceamento nutricional, constituindo-se em alimento básico para bilhões de pessoas no mundo, sendo considerado um dos mais importantes produtos em termos de valor econômico e social em muitos países em desenvolvimento.

O Brasil está entre os dez principais produtores mundiais de arroz, com cerca de 11 milhões de toneladas e também entre os maiores importadores, absorvendo cerca de 5\% do volume das exportações mundiais (Embrapa, 2009). Dezesseis estados de todas as regiões do país produzem arroz irrigado sob condições climáticas muito distintas. Dentre eles, os principais produtores são o Rio Grande do Sul, Santa Catarina, Mato Grosso, Maranhão e Pará, sendo o Rio Grande do Sul o maior produtor, contribuindo com 25,6\% do total da área produzida (Conab, 2009).

Baseado na importância da cultura, assim como no crescente consumo, são necessárias novas tecnologias que possibilitem aumentar a produção de sementes de alta qualidade que atendam a crescente demanda dos agricultores por cultivares adaptadas, mais produtivas e que possam gerar retorno ao investimento realizado pelo produtor.

Apesar dos avanços conseguidos com o melhoramento genético na busca de genótipos tolerantes a doenças, ainda é grande a incidência de doenças fúngicas que, além de causarem queda na produtividade, afetam a qualidade das sementes. Em arroz irrigado, um grande número de patógenos atua de forma incisiva no estádio reprodutivo e de maturação da cultura, o que pode refletirse em sementes de baixa qualidade fisiológica e sanitária (Nakamura e Sader, 1986). Algumas pesquisas têm demonstrado que a adubação com silício antes do plantio pode ser eficiente na redução da severidade de doenças importantes do arroz, como bruzone, mancha parda, entre outras. Estas doenças tendem a diminuir com o aumento da concentração de silício no tecido foliar (Datnoff et al.,1991; Korndorfer e Datnoff, 1995; Korndorfer et al. 1999; Datnoff et al., 2001).
Mesmo não sendo essencial, do ponto de vista fisiológico, para o crescimento e desenvolvimento das plantas (Epstein, 1994), a absorção de silício trás inúmeros benefícios, principalmente para a cultura do arroz. Isto mostra a "essencialidade agronômica" deste elemento para um aumento e/ou produção sustentável desta cultura.

Apesar da necessidade de maior número de estudos nessa área, pesquisas recentes desenvolvidas sobre o efeito da utilização de silício em arroz, vêm despertando bastante interesse entre técnicos e agricultores, devido aos inúmeros benefícios que ele poderá trazer à cultura, incluindo aumentos na produtividade e qualidade de sementes, na redução da incidência de doenças fúngicas, na melhoria da fertilidade do solo, na redução de custos e impactos ambientais, dentre outros.

Segundo Lee et al. (1985), o silício tem efeito direto e indireto no crescimento do arroz e aplicações de silicato de cálcio levaram ao aumento do número de folhas e o peso de matéria seca das plantas. A maior expansão foliar determina maior taxa de assimilação de gás carbônico por planta. Com isso, há maior translocação de assimilados para a produção de grãos, aumentando a produtividade (Lima Filho, 2009). Nesse sentido e de acordo com trabalhos realizados por Savant et al.(1997) e Faria Júnior (2007), a redução nos teores de silício em solos intensamente cultivados com arroz irrigado é tão pronunciada que foi considerada a causa do declínio da produção de arroz.

Apesar de existirem estudos com silício em alguns países, no Brasil praticamente não há trabalhos demonstrando a sua eficiência na produção de sementes de arroz de alta qualidade. Nesse contexto, buscou-se com a presente pesquisa avaliar a influência da aplicação de doses de silício no desempenho de sementes de arroz irrigado, produzido no estado de Minas Gerais e armazenadas por um período de seis meses.

\section{MATERIAL E MÉTODOS}

A pesquisa foi conduzida no Laboratório Central de Sementes da Universidade Federal de Lavras (UFLA), no município de Lavras - MG. Foram utilizadas sementes 
genéticas de arroz, produzidas pela Empresa de Pesquisa Agropecuária de Minas Gerais (EPAMIG), em dois experimentos conduzidos nas Fazendas Experimentais em Lambari e Leopoldina em sistema de irrigação por inundação. Utilizaram-se sementes da cultivar Jequitibá, consideradas semi-precoces e suscetíveis a bruzone.

Foram testadas quatro doses de silicato de cálcio $\left(0,800,1.600\right.$ e $\left.3.200 \mathrm{~kg} \mathrm{ha}^{-1}\right)$ como fonte de silício, aplicadas 30 dias antes do plantio nos dois ensaios. As unidades experimentais foram compostas de seis linhas de $5 \mathrm{~m}$ de comprimento, espaçadas de $0,30 \mathrm{~m}$ entre si, com densidade de 100 sementes $/ \mathrm{m}$, resultando em um estande final de aproximadamente 80 plantas $/ \mathrm{m}$. A área útil para tomada de dados foi de $3,6 \mathrm{~m}^{2}$ provenientes das três linhas centrais, deixando-se $0,50 \mathrm{~m}$ em cada extremidade. $\mathrm{O}$ restante da parcela foi considerado bordadura. A adubação de plantio foi feita de acordo com a análise de solo e conforme Recomendações para o Uso de Corretivos e Fertilizantes de Minas Gerais $5^{\text {a }}$ aproximação (CFS-MG, 1999). Aplicaram-se, ainda, $60 \mathrm{~kg} \mathrm{ha}^{-1}$ de $\mathrm{N}$ em cobertura, aos 70 dias após o plantio. Com relação à presença de silício nos solos, detectou-se em análise realizada antes do experimento, $5,5 \mathrm{mg} / \mathrm{dm}^{3}$ de Si em Lambari e 7,5 mg/ $\mathrm{dm}^{3}$ em Leopoldina, solos esses classificados como de baixo e médio teor de $\mathrm{Si}$, de acordo com Korndorfer et al. (2001).

O controle de plantas daninhas foi feito com o herbicida oxadiazon $\left(0,750 \mathrm{~L} \mathrm{ha}^{-1}\right)$ em pré-emergência e dois herbicidas em pós-emergência precoce, sendo o metsulfuron-methyl $\left(2,0 \mathrm{~g} \mathrm{ha}^{-1}\right)$ utilizado para o controle de plantas daninhas latifoliadas e o herbicida prefoxydim $(170,0$ $\mathrm{g} \mathrm{ha}^{-1}$ ) para o controle de plantas daninhas gramíneas.

Após as sementes atingirem teor de água de $20 \%$, foi feita a colheita das plantas manualmente e as sementes foram secadas a sombra até atingirem teor de água de, aproximadamente, $13 \%$; a seguir, forambeneficiadas. Quatro amostras de $1 \mathrm{~kg}$ de cada tratamento foram acondicionadas em embalagens de papel e armazenadas por um período de seis meses em câmara fria, com temperatura de $9+1$ ${ }^{\circ} \mathrm{C}$ e umidade relativa de $48+2 \%$. As avaliações relativas à qualidade das sementes foram realizadas entre 0,3 e 6 meses por meio das seguintes determinações:

Teor de água: Determinou-se pelo método da estufa a $105+3{ }^{\circ} \mathrm{C}$, durante 24 horas, com duas repetições para cada tratamento, conforme prescrições das Regras para Análise de Sementes (Brasil, 2009). Os resultados foram expressos em porcentagem.

Germinação: Foram utilizadas quatro repetições de 50 sementes por tratamento, semeadas em rolos de papel tipo "Germitest" e posteriormente mantidas em germinador a uma temperatura de $25^{\circ} \mathrm{C}$. A quantidade de água adicionada foi de 2,5 vezes o peso do papel, visando umedecimento adequado e uniformização do teste. As avaliações (7 e 14 dias) foram realizadas segundo prescrições das Regras para Análise de Sementes-RAS (Brasil, 2009). Computaram-se as porcentagens de plântulas normais, as quais correspondem à porcentagem de germinação.

Envelhecimento acelerado: Foi realizado utilizandose o método do gerbox adaptado. Dentro de cada gerbox, contendo $40 \mathrm{~mL}$ de água destilada, colocaram-se 200 sementes de cada tratamento em camada única sobre uma tela suspensa. Essas caixas foram colocadas em câmara de germinação (BOD), a uma temperatura de $42{ }^{\circ} \mathrm{C}$ por 120 horas. Após este período as sementes foram colocadas para germinar seguindo a metodologia descrita para $\mathrm{o}$ teste de germinação.

Emergência de plântulas: A semeadura foi feita em canteiro contendo como substrato areia acrescida de solo classificado como Latossolo Vermelho (LV), na proporção $2: 1$, sendo esta realizada em sulcos com profundidade de $2 \mathrm{~cm}$. Utilizaram-se quatro repetições de 50 sementes por tratamento. A partir da emergência da primeira plântula, as avaliações foram diárias, computando-se o número de plântulas emergidas até a estabilização. Foram consideradas as porcentagens de plântulas emergidas e também o índice de velocidade de emergência (IVE), calculado segundo a fórmula proposta por (Maguire, 1962).

Determinação de atividades isoenzimáticas: Para a caracterização bioquímica foram utilizadas 200 sementes de cada tratamento, as quais foram acondicionadas em sacos plásticos devidamente identificados, lacrados e armazenados em deep-freezer $\left(-86{ }^{\circ} \mathrm{C}\right)$ até a realização das devidas extrações. Para a extração das enzimas as sementes foram maceradas em moinho refrigerado com nitrogênio líquido na presença de $5 \mathrm{mg}$ do antioxidante PVP (Polivinilpirrolidona). A seguir, adicionaram-se à aproximadamente 100 mg do pó da semente de cada amostra, $250 \mu 1$ de tampão de extração Tris - $\mathrm{HCl}(0,2 \mathrm{M} \mathrm{pH} \mathrm{8,0} \mathrm{e} 0,1 \%$ de $\beta$-mercaptoetanol). As amostras contidas em micro tubos foram então agitadas em vórtex por 1 minuto e colocadas em geladeira overnight. Após esse período elas foram centrifugadas a $14.000 \mathrm{rpm}$, por 30 minutos a $4{ }^{\circ} \mathrm{C}$ e, $50 \mu \mathrm{L}$ do sobrenadante foram então aplicados 
no gel de corrida sistema descontínuo, gel separador, poliacrilamida $7,5 \%$ e gel concentrador, poliacrilamida $4,5 \%$. O sistema tampão gel/eletrodo utilizado foi o tris-glicina $\mathrm{pH} 8,9$. As corridas eletroforéticas foram efetuadas a $120 \mathrm{~V}$, por 6 horas e ao término, os géis foram coloridos histoquimicamente. Os procedimentos de preparo dos géis, a eletroforese e a coloração histoquímica foram realizadas segundo protocolos estabelecidos por Alfenas (2006), sendo testados os sistemas enzimáticos catalase (CAT) e esterase (EST).

$\mathrm{O}$ delineamento experimental utilizado foi $\mathrm{O}$ inteiramente casualizado, em esquema fatorial $4 \times 3$, sendo quatro doses de silicato de cálcio $(0,800,1.600,3.200$ $\left.\mathrm{kg} \mathrm{ha}^{-1}\right)$ e três épocas de avaliação (0, 3 e 6 meses), com quatro repetições, em cada local de plantio isoladamente. Foram realizadas análises de variância para todas as características analisadas, exceto para a determinação das atividades isoenzimáticas. As variáveis que apresentaram efeito significativo pelo teste $\mathrm{F}$ foram estudadas por meio de análise de regressão com auxílio do programa estatístico SISVAR ${ }^{\circledR}$ (Ferreira, 2000).

\section{RESULTADOS E DISCUSSÃO}

\section{Avaliações fisiológicas}

Observou-se que as sementes produzidas, tanto em Lambari quanto em Leopoldina, praticamente mantiveram seu teor de água inalterado (em torno de 11,5\%), durante o armazenamento, umidade considerada adequada para o armazenamento de sementes de arroz nas referidas condições.

\section{Sementes produzidas em Lambari}

$\mathrm{Na}$ Tabela 1 observa-se que os melhores resultados de germinação foram aos 3 meses de armazenamento, o que sugere a ocorrência da superação da dormência inicial das sementes. De acordo com Lopes et al. (1998), a partir dos 3 meses de armazenamento as cultivares de arroz tem um aumento significativo na germinação em relação à germinação inicial, antes do armazenamento, provavelmente devido à superação natural da dormência. Segundo Vieira et al. (2002), a dormência é mais intensa logo após a colheita nas cultivares irrigadas do que nas de sequeiro. Entretanto, pode ser observado ainda, que no final do armazenamento, aos 6 meses, os valores encontrados para a germinação são estatisticamente iguais àqueles observados aos 3 meses, embora tenha havido um pequeno decréscimo na germinação.
TABELA 1. Valores médios de germinação de sementes de arroz, cultivar Jequitibá, produzidas no sistema irrigado por inundação, em solos com baixo teor de Si (Lambari), em função de épocas de armazenamento.

\begin{tabular}{cc}
\hline Época (meses) & Germinação $(\%)$ \\
\hline 0 & $81,3 \mathrm{~b}$ \\
3 & $88,6 \mathrm{a}$ \\
6 & $85,9 \mathrm{a}$ \\
\hline $\mathrm{CV}(\%)$ & 6,62 \\
\hline
\end{tabular}

Médias seguidas da mesma letra não diferem entre si pelo teste de ScottKnott aos 5\% de probabilidade

Para os resultados do teste de germinação em função de diferentes doses de silício (Figura 1), verifica-se que houve uma tendência de acréscimo na germinação das sementes com a aplicação do silicato de cálcio até a dose de $1.600 \mathrm{~kg} \mathrm{ha}^{-1}$. A partir daí a tendência foi de redução na germinação, embora em proporções pequenas, até a dose mais elevada (3.200 ha-1), porém com uma germinação encontrada nessa dose, superior à testemunha.

Observa-se na Figura 2, para o teste de envelhecimento acelerado, que para a época 1 (antes do armazenamento), a aplicação do silício na dosagem de $800 \mathrm{~kg} \mathrm{ha}^{-1}$ de silicato de cálcio proporcionou acréscimo na geminação. Nesse caso o teste pode ter funcionado como um tratamento para superar a dormência das sementes. Entretanto, nas dosagens maiores, a partir de $1.600 \mathrm{~kg} \mathrm{ha}^{-1}$, a tendência foi de decréscimo, podendo esse fato estar relacionado a uma fitotoxidez causada pelo nutriente sobre influência das condições do teste. Já durante o armazenamento, nas épocas dois ( 3 meses) e três (6 meses), verificase que houve tendência de acréscimo na germinação após o envelhecimento acelerado à medida que as doses de silicato de cálcio foram aumentadas, tendo maior incremento na dose de $3.200 \mathrm{~kg} \mathrm{ha}^{-1}$ para ambas as épocas. Nesse caso possivelmente o armazenamento tenha contribuído para minimizar a influência da fitotoxidez. Há de se considerar também que, após 3 meses de armazenamento, a dormência das sementes, provavelmente, foi superada. Nesse contexto, Lopes et al. (1998) observaram que o teste de envelhecimento acelerado com $100 \%$ de UR e $43{ }^{\circ} \mathrm{C}$ por $24,48,72$, 96 e 120 horas determinou a redução no nível de 
dormência, com conseqüente aumento no vigor das sementes de arroz. De maneira semelhante, Vieira et al. (2002) relatam que o teste de vigor pelo método de envelhecimento artificial nos primeiros meses pode funcionar como um tratamento para superar a dormência.

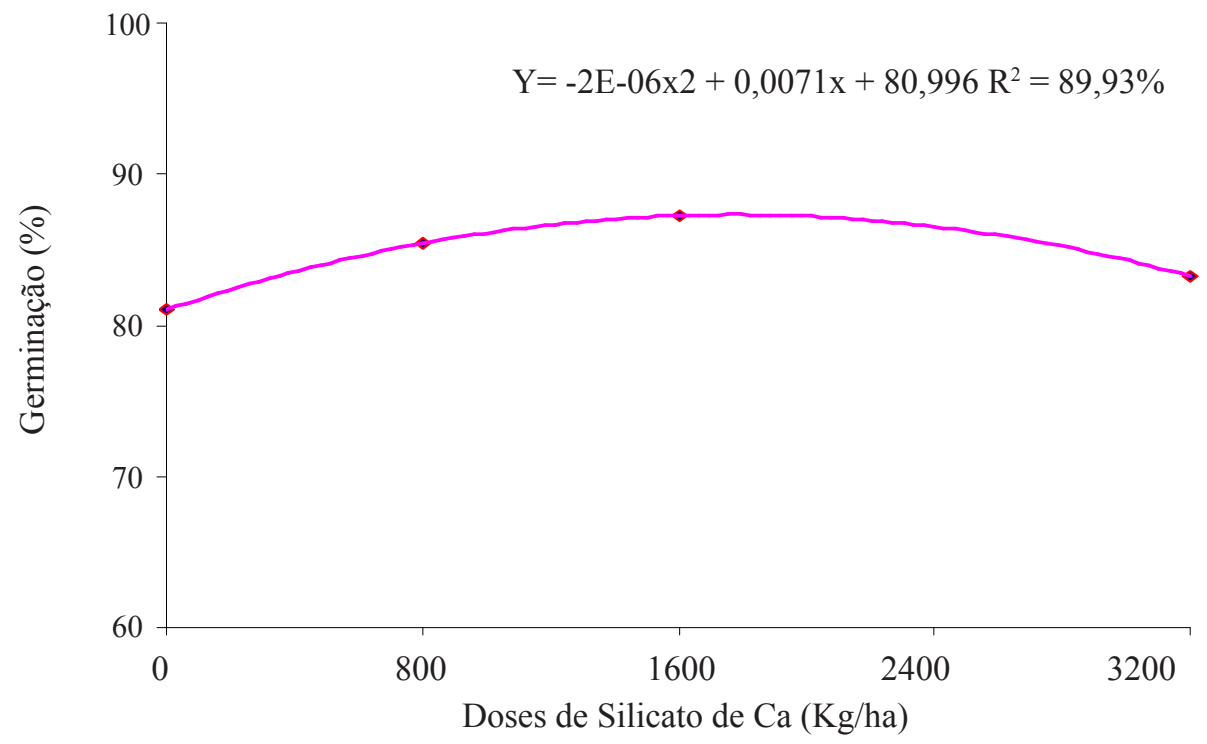

FIGURA 1. Porcentagem de germinação de sementes de arroz, cultivar Jequitibá, produzidas no sistema irrigado por inundação, em solos com baixo teor de Si (Lambari), em função de diferentes doses de silicato de cálcio.

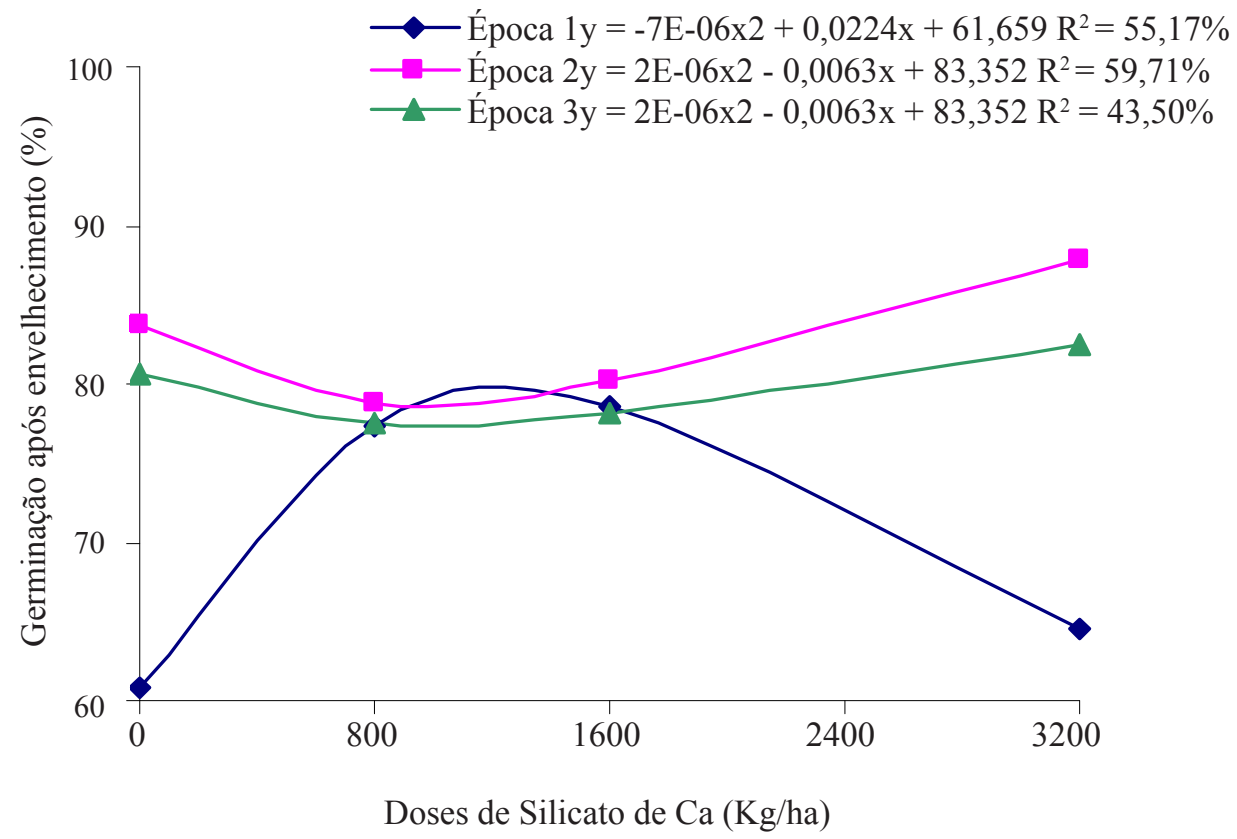

FIGURA 2. Porcentagem de germinação após teste de envelhecimento acelerado, para as diversas doses de silicato de cálcio aplicadas, em relação ao mês 0 (Época 1), 3 meses (Época 2) e 6 meses (Época 3) de armazenamento, para sementes de arroz cultivar Jequitibá, produzidas no sistema irrigado por inundação, em solos com baixo teor de Si (Lambari). 


\section{Sementes Produzidas em Leopoldina}

$\mathrm{Na}$ avaliação da germinação (Figura 3), pode-se observar que, para as épocas 1 e 3 surgem a tendência de dados decrescentes para germinação quando aumenta-se as dosagens de silicato de cálcio. Deve-se considerar aí, uma possível dormência das sementes na época 1 assim como maior fitotoxidez na época 3 com a utilização de doses mais elevadas do produto. Em doses menores (800 $\mathrm{kg} \mathrm{ha}^{-1}$ ) ou até mesmo na ausência de silício, como no tratamento testemunha, verificam-se maiores porcentagens de germinação, quando se faz a comparação entre todas as épocas de armazenamento.

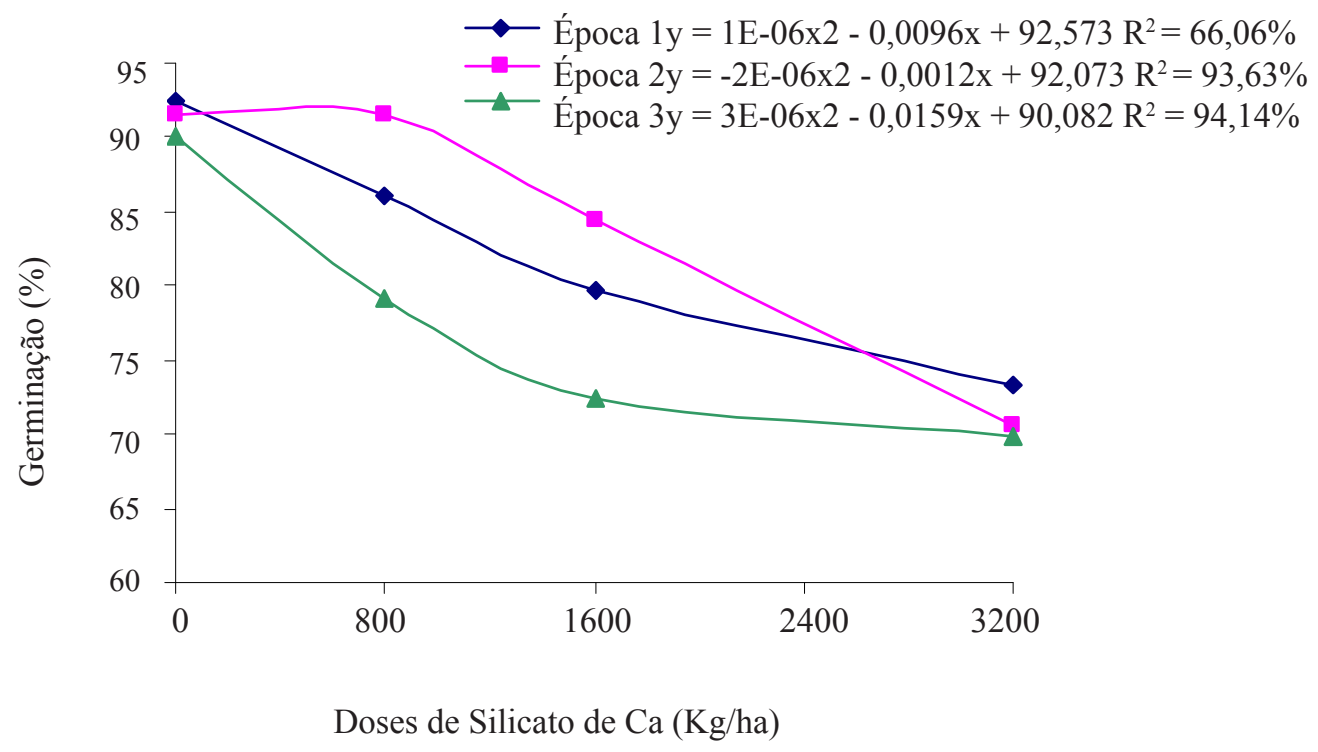

FIGURA 3. Porcentagem de germinação para as diversas doses de silicato de cálcio aplicadas em relação ao mês 0 (Época 1), 3 meses (Época 2) e 6 meses (Época 3) de armazenamento, para sementes de arroz cultivar Jequitibá, produzidas no sistema irrigado por inundação em solos com médio teor de Si (Leopoldina).

Pelos resultados do vigor das sementes avaliado por meio do teste de envelhecimento acelerado, para as diversas doses de silicato de cálcio aplicadas em relação às diferentes épocas de armazenamento, verifica-se na Figura 4 que, para a época 3 (6 meses) houve um incremento na germinação quando se utilizaram $800 \mathrm{~kg} \mathrm{ha}^{-1}$ de silicato de cálcio. Porém, para as demais épocas a influência dessa dosagem não foi relevante, havendo pequeno decréscimo na época 1 (mês 0 ) e pequeno acréscimo na época 2 ( 3 meses). No entanto, as dosagens maiores que $800 \mathrm{~kg} \mathrm{ha}^{-1}$ de silicato de cálcio provocaram decréscimos acentuados no vigor nas três épocas de armazenamento. Essa tendência de redução na germinação das sementes de arroz após o teste de envelhecimento acelerado antes do armazenamento pode estar relacionada a uma possível toxidez causada pelas dosagens mais elevadas do produto utilizado, conforme já discutido anteriormente nos resultados da Figura 2, para as sementes produzidas em Lambari, assim como para os resultados da Figura 3. No entanto, quanto ao armazenamento de uma maneira geral, a qualidade das sementes tende a diminuir ao longo do período por melhor que seja o acondicionamento. Embora nesse caso as sementes armazenadas tenham apresentado tendência de menor decréscimo nos resultados encontrados para o teste de germinação, eles estão de acordo com Delouche (1981) e Justice e Bass (1978), os quais relatam de maneira geral que a velocidade de deterioração das sementes é influenciada por fatores genéticos, formas de manipulação e condições de armazenamento. 


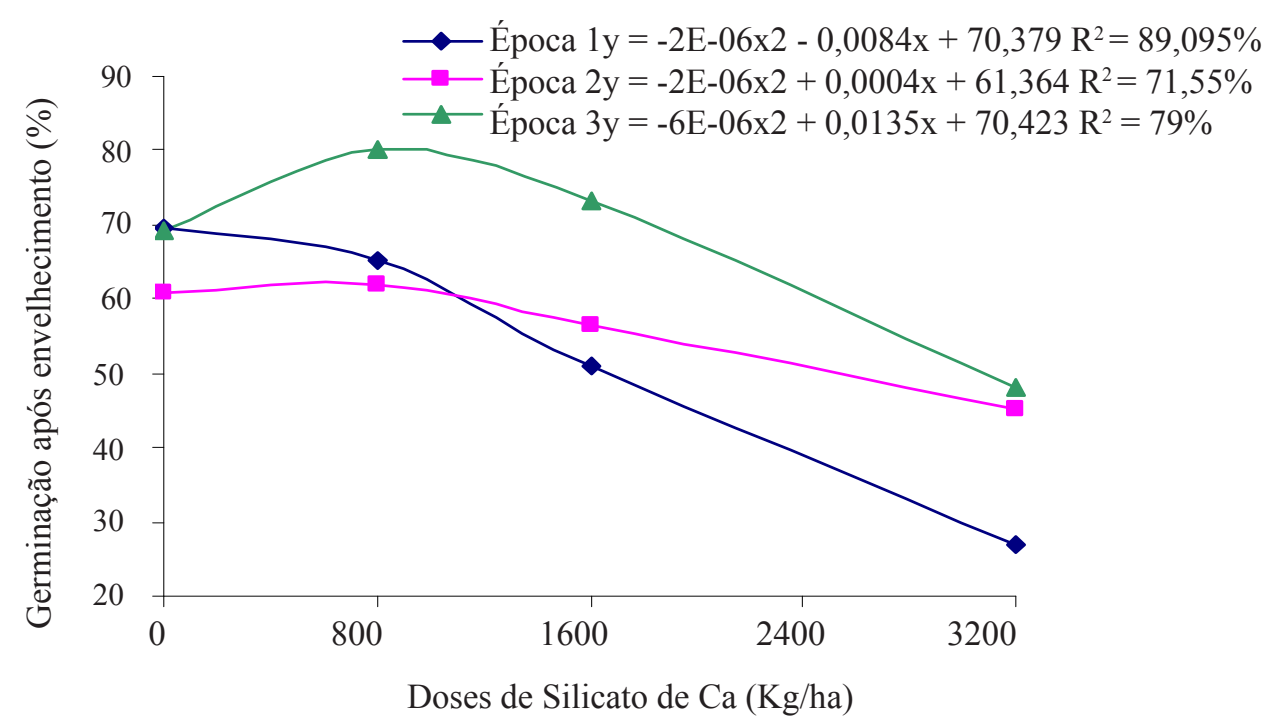

FIGURA 4. Porcentagem de germinação após teste de envelhecimento acelerado, para as diferentes doses de silicato de cálcio aplicado, em relação ao mês 0 (Época 1), 3 meses (Época 2) e 6 meses (Época 3) de armazenamento, para sementes de arroz cultivar Jequitibá, produzidas no sistema irrigado por inundação em solos com médio teor de Si (Leopoldina).

Nas Figuras 5 e 6, verifica-se que os resultados do efeito das doses de silício aplicadas, sobre o vigor das sementes, determinado por meio dos testes de emergência e índice de velocidade de emergência, tendem a ter maiores valores para as dosagens 0 (testemunha). Acima desses valores a resposta não foi positiva. Essa tendência pode estar relacionada, conforme já suposto anteriormente, a uma possível toxidez causada pelas dosagens mais elevadas do produto utilizado.

De uma maneira geral, verifica-se que, embora tenha havido pequenas divergências nos resultados encontrados nos dois locais estudados, onde os solos têm teores de silício de $5,5 \mathrm{mg} / \mathrm{dm}^{3}$ em Lambari e 7,5 $\mathrm{mg} / \mathrm{dm}^{3}$ em Leopoldina, classificados como de baixo e médio teor em Si, de acordo com Korndorfer et al. (2001), a ausência de uma maior resposta à aplicação de Si pode estar relacionada a cultivar utilizada. Algumas delas podem extrair os elementos mais eficientemente do que outras, mesmo em solos deficientes, o que pode ser explicado por seus mecanismos fisiológicos com diferentes taxas de absorção e translocação e diferenças morfológicas nos seus sistemas radiculares (Malavolta; Fornasiere Filho, 1983; Lopes, 1996). Essa hipótese é ressaltada por Winslow (1992) e Barbosa Filho et al. (1998), que relataram que há diferença genotípica quanto à capacidade de absorver Si. Assim, a elevação nos teores do elemento no solo para níveis considerados adequados passa a ser importante, uma vez que não se conhece a exigência das cultivares de arroz em relação ao Si.

\section{Determinações das atividades isoenzimáticas}

Os padrões eletroforéticos da enzima esterase, para as sementes produzidas tanto em Lambari quanto em Leopoldina, estão representados na Figura 7. Observase que, embora em algumas situações, tenha havido um pequeno aumento na atividade dessa enzima quando se utilizaram dosagens menores de silicato de cálcio, ocorreu um pequeno decréscimo na intensidade de bandas para a dosagem de $3.200 \mathrm{~kg} \mathrm{ha}^{-1}$ (T4 e T8), sugerindo que a aplicação de silicato de cálcio não favoreceu a qualidade das sementes. No entanto, pode-se verificar que a atividade da esterase nas sementes de arroz, de uma maneira geral, aumentou durante o armazenamento, indicando um maior envelhecimento das sementes. Esses resultados podem ser comparados àqueles encontrados para a germinação 
(Figura 4), os quais têm bastante semelhança. Alterações nos padrões da esterase são evidências da ocorrência de eventos deteriorativos, pois é uma enzima envolvida em reações de hidrólise de ésteres e está diretamente ligada ao metabolismo de lipídios e ao processo degenerativo de membranas (Santos et al., 2004). Shatters et al. (1994) observaram aumento na atividade total dessa enzima com o envelhecimento de sementes de soja. Ribeiro (2000) também observou aumento no número de bandas de esterase em sementes de algodão, com o envelhecimento artificial.

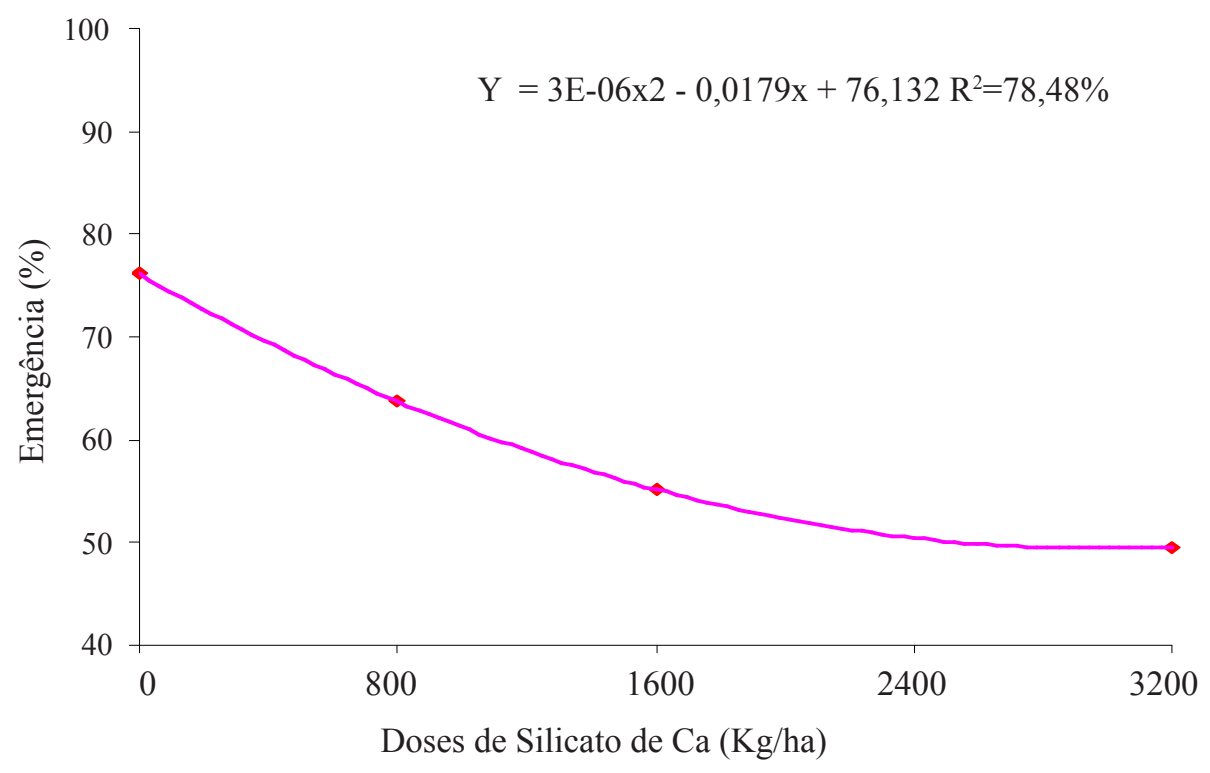

FIGURA 5. Porcentagem de emergência de sementes de arroz, cultivar Jequitibá, produzidas no sistema irrigado por inundação em solos com médio teor de Si (Leopoldina), em função de diferentes doses de silicato de cálcio.

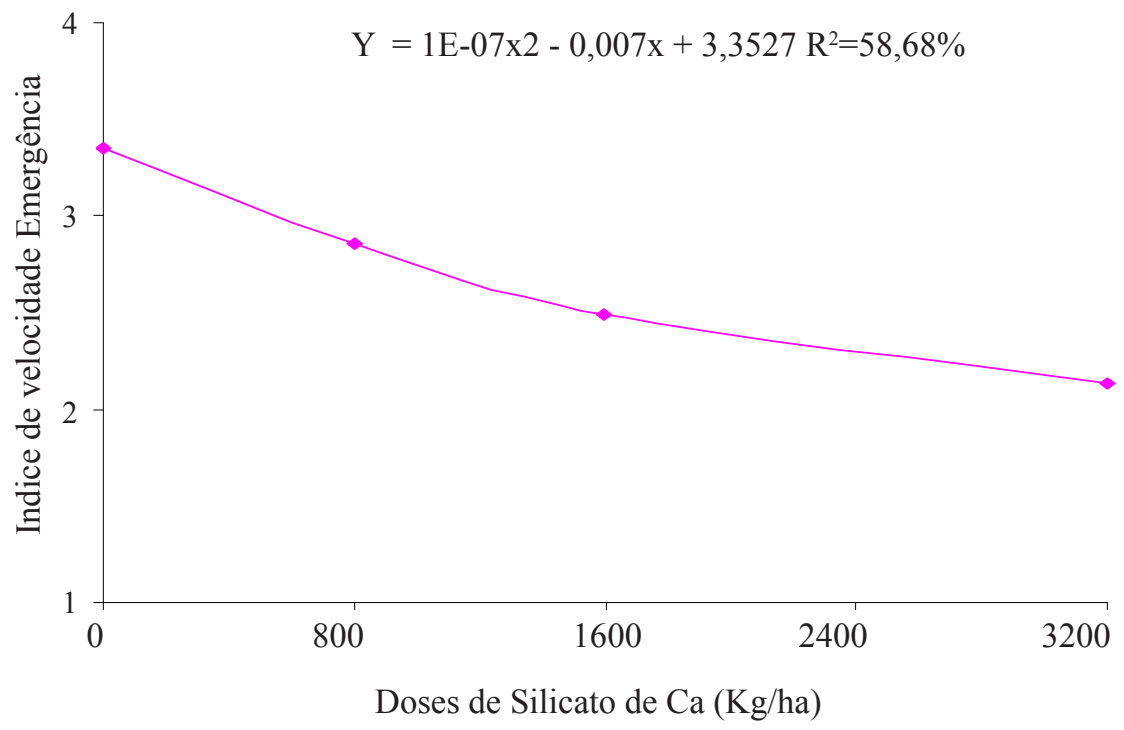

FIGURA 6. Valores médios de índice de velocidade de emergência de sementes de arroz, cultivar Jequitibá, produzidas no sistema irrigado por inundação em solos com médio teor de Si (Leopoldina), em função de diferentes doses de silicato de cálcio. 


\section{Lambari- MG}

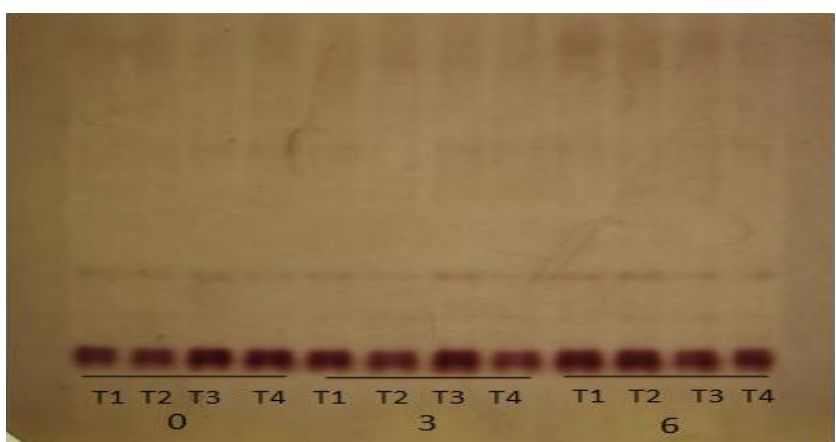

\section{Leopoldina -MG}

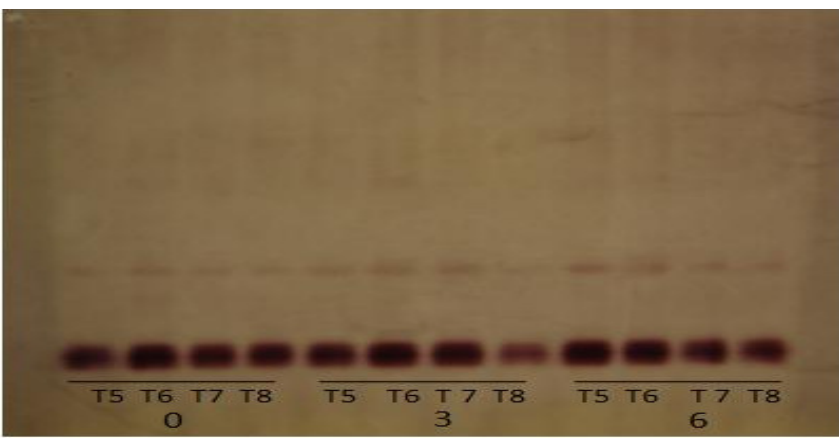

FIGURA 7. Padrões da enzima esterase em sementes de arroz, cultivar Jequitibá, produzidas com diferentes doses de silicato de cálcio, no sistema irrigado por inundação, em solos com baixo teor de Si em Lambari (T1 (0 kg/ha), T2 (800 kg/ha), T3 (1.600 kg/ha) e T4 (3.200 kg/ha) e em solos com médio teor de Sí em Leopodina (T5 ( $0 \mathrm{~kg} / \mathrm{ha})$, T6 (800 kg/ha), T7 (1.600 kg/ha) e T8 $(3.200 \mathrm{~kg} / \mathrm{ha})$ e avaliadas em diferentes épocas de armazenamento.

Lambari- MG

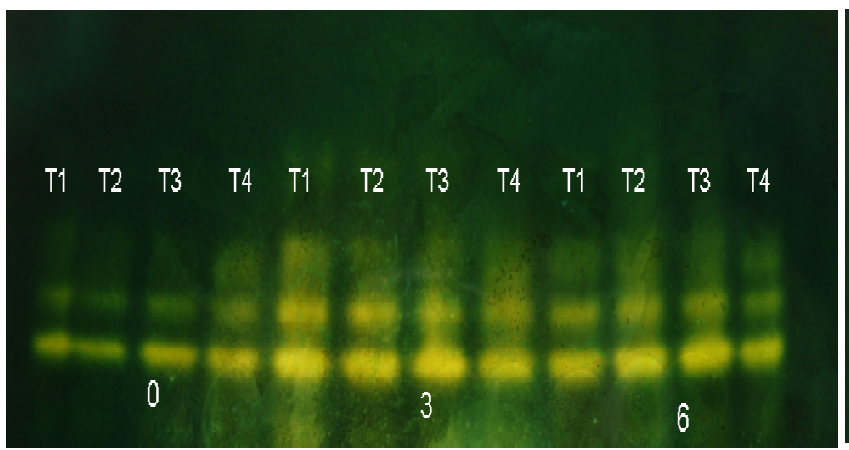

Leopoldina- MG

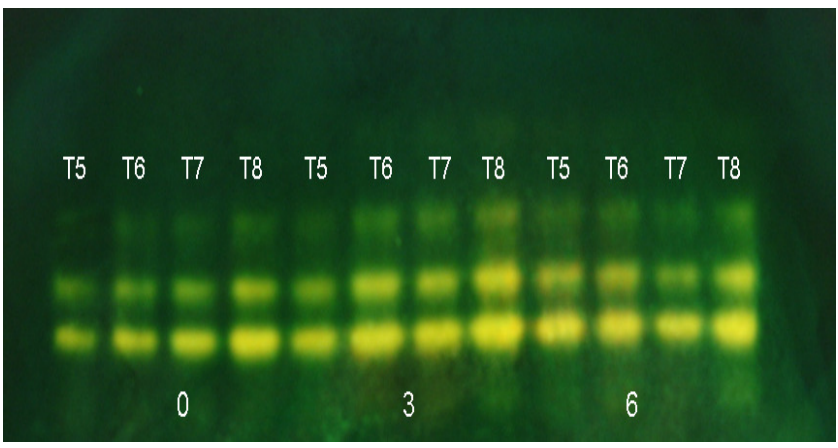

FIGURA 8. Padrões da enzima catalase em sementes de arroz, cultivar Jequitibá, produzidas com diferentes doses de silicato de cálcio, no sistema irrigado por inundação, em solos com baixo teor de Si em Lambari T1 (0 kg/ha), T2 (800 kg/ha), T3 (1.600 kg/ha) e T4 (3.200 kg/ha) e em solos com médio teor de Sí em Leopoldina T5 ( $0 \mathrm{~kg} / \mathrm{ha})$, T6 (800 kg/ha), T7 (1.600 kg/ha) e T8 $(3.200 \mathrm{~kg} / \mathrm{ha})$ e avaliadas em diferentes épocas de armazenamento .

Pelos resultados encontrados para a atividade das enzimas esterase e catalase, não se pode concluir com consistência, que elas são eficientes indicadores da qualidade fisiológica das sementes de arroz produzidas sob adubação com silicato de cálcio e armazenadas, no entanto pode-se notar maior intensidade de bandas de catalase e menor para esterase em sementes produzidas em solos com média quantidade de silício (Leopoldina) em dosagens de
$3.200 \mathrm{~kg} \mathrm{ha}^{-1} \mathrm{o}$ que coincide com os resultados inferiores de vigor e germinação.

\section{CONCLUSÕES}

Em Lambari, local de solos com baixo teor de Si, há efeito favorável do silicato de cálcio na qualidade das sementes. 
Em Leopoldina, local de solos com médio teor de Si, a aplicação de silicato de cálcio é prejudicial à qualidade das sementes.

O silicato de cálcio aplicado no plantio de arroz em solos com baixo níveis de Si tem efeito positivo na qualidade das sementes produzidas. Dosagens excessivas de $\mathrm{Si}$ podem afetar negativamente a qualidade das sementes.

\section{AGRADECIMENTOS}

À Fundação de Apoio à Pesquisa do Estado de Minas Gerais - FAPEMIG, pelo financiamento da pesquisa.

\section{REFERÊNCIAS}

ALFENAS, A.C. Eletroforese e marcadores bioquímicos em plantas e microorganismos. 2.Ed. Viçosa: Ed. UFV, 2006. 627p.

BAILLY, C.; BOGATEK-LESZCZYNSKA, R.; CÔME, D.; CORBINEAU, F. Changes in activities of antioxidant enzymes and lipoxygenase during growth of sunflower seedlings from seeds of different vigour. Seed Science Research, v.12, n.1, p.47-55, 2002.

BARBOSA FILHO, M.P.; SNYDER, G.H.; ELLIOTT, C.L.; DATNOFF, L.E.; PRABHU, A.S.; SILVA, O.F.; KORNDORFER, G.H. Resposta do arroz de sequeiro à aplicação de silício. In: FERTBIO 1998, Caxambu. Anais... Lavras: UFLA/SBCS, 1998. p.57.

BRASIL. Ministério da Agricultura, Pecuária e Abastecimento. Regras para análise de sementes. Ministério da Agricultura, Pecuária e Abastecimento. Secretaria de Defesa Agropecuária. Brasília, DF: Mapa/ ACS, 2009. 395p.

COMISSÃO DE FERTILIDADE DO SOLO DO ESTADO DE MINAS GERAIS. Recomendações para o uso de corretivos e fertilizantes em Minas Gerais. $5^{\text {a }}$. aproximação. Viçosa, 1999. 355p.

COMPANHIA NACIONAL DE ABASTECIMENTO. Acompanhamento da safra brasileira. Disponível em: < http://www.conab.gov.br/>. Acesso em: 30 de abr. 2009.

CORNÉLIO, V.M.O.; REIS, M.S.; SOARES, A.A.; SOARES, P.C.; MESQUITA, H.A.; SILVA, R.A.; SOUZA, J.C.; SOUZA, V.C.O.; VIEIRA, A.R. A cultura do arroz e a agricultura familiar. Informe Agropecuário, v.31, n.254, p.28-34, 2010.

DATNOFF, L.E.; KORNDORFER, G.H.; SNYDER, G.H.
Silicon in agriculture. Elsevier Science: Amsterdam, 2001. 424p. (Book Series Studies in Plant Science, v.8).

DATNOFF, L.E.; RAID, R.N.; SNYDER, G.H.; JONES, D.B. Effect of calcium silicate on blast and brown spot intensities and yields of rice. Plant Disease, v.75, n.7, p.729-732, 1991.

DELOUCHE, J.C. Metodologia de pesquisa em sementes. II. Secagem, beneficiamento e armazenamento. Revista Brasileira de Sementes, v.3, n.2, p.48-55, 1981.

DROCHIOIU, G.; CRISTEA, M.; STRAJERU, S. Catalase activity of maize seeds in the process of forced aging. Cercetari Agronomice in Moldova, v.26, n.1, p.19-25, 1993.

EMPRESA BRASILEIRA DE PESQUISA AGROPECUÁRIA. Sistemas de produção. Disponível em: $<$ http://sistemasdeproducao.cnptia.embrapa.br $>$. Acesso em: 20 de maio de 2009.

EPSTEIN, E. The anomaly of silicon in plant biology. Proceedings of the National Academy of Science, v.91, n.1, p.11-17, 1994.

FARIA JÚNIOR, L.A. Respostas de cultivares de arroz de terras altas (Oryza sativa L.) ao silício. 2007. 52p. Dissertação (Mestrado)- Universidade Federal de Lavras, Lavras, MG. 2007.

FERREIRA, D.F. Análises estatísticas por meio do SISVAR para Windows versão 4.0. In: REUNIÃO ANUAL DA REGIÃO BRASILEIRA DA SOCIEDADE INTERNACIONAL DE BIOMETRIA, 45., 2000, São Carlos. Programas e resumos... São Carlos: UFSCar, 2000. p.235.

JUSTICE, O.L.; BASS, L.N. Principles and practices of seed storage. Agriculture Handbook, v.506, p.289, 1978.

KORNDORFER, G.H.; DATNOFF, L.E. Adubação com silício: uma alternativa no controle de doenças da cana-deaçúcar e do arroz. Informações Agronômicas, n.70, p1-3, 1995.

KORNDORFER, G.H.; SNYDER, G.H.; ULLOA, M.; POWEL, J.; DATNOFF, L.E. Calibration of soil and plant silicon analysis for rice production. Journal of Plant Nutrition, v.24, n.7, p.10711084, 2001.

KORNDORFER, G.H.; ARANTES,V.A.; CORREA, G.F.; SNYDER, G.H. Efeito do silicato de cálcio no teor de silício no solo e na produção de grãos de arroz de sequeiro. Revista Brasileira de Ciência do Solo, v.23, n.3, p.635$641,1999$. 
LEE, K.S.; AHN, S.B.; RHEE, G.S.; YEON, B.Y.; PARK, J.K. Studies of sílica application to nursery beds on Rice seedling growth. Research Report. Rural Development Administration, Plant Environment, Mycology, Farm Product Utilization of the Korea Replubic, v.27, n.1, p.23-27, 1985.

LIMA FILHO, O.F. de. Produtividade e manejo do solo: o caso do silício. Dourados: Embrapa Agropecuária Oeste. Disponível em:< http://www.cpao.embrapa.br/portal/ artigos/artigos/artigo1.html>. Acesso em: 20 maio 2009.

LOPES, A.S. Guia das melhores técnicas agrícolas. São Paulo: ANDA, 1996. 28p.

LOPES, J.C.; CAPUCHO, M.T.; FURNO, P.S.; ZANOTTI, P. Tratamentos para superar a dormência em sementes de arroz (Oryza sativa L.). Revista Brasileira de Sementes, v.20, n.1, p.87-92, 1998.

MAGUIRE, J. Speed of germination aid in selection and evoluation for seedling and vigour. Crop Science, v.2, n.2, p.176-177, 1962.

MALAVOLTA, E.; FORNASIERI FILHO, D. Nutrição mineral da cultura do arroz. In: FERREIRA, M.E.; YAMADA, T.; MALAVOLTA, E. Cultura do arroz de sequeiro: fatores afetando a produtividade. Piracicaba, 1983. p. $95-143$.

McDONALD, M.B. Seed deterioration: physiology, repair and assessments. Seed Science and Technology, v.27, n.1, p. 177-237, 1999.

NAKAMURA, A.M.; SADER, R. Efeito da infecção por fungos na germinação e vigor de sementes de arroz. Revista Brasileira de Sementes, v.8, n.1, p.101-111, 1986.
RIBEIRO, U.P. Condicionamento fisiológico de sementes de algodão: efeitos sobre a germinação, vigor, atividade enzimática e armazenabilidade. 2000. 79f. Dissertação (Mestrado em Fitotecnia) - Universidade Federal de Lavras, Lavras, MG. 2000.

ROSA, S.D.V.F. DA; VON PINHO, E.V.R.; VIEIRA, E.S.N.; VEIGA, R.D.; VEIGA, A.D. Enzimas removedoras de radicais livres e proteínas lea associadas à tolerância de sementes milho à alta temperatura de secagem. Revista Brasileira de Sementes, v.27, n.2, p.91-101, 2005.

SANTOS, C.M.R.; MENEZES, N.L.; VILLELA, F.V. Alterações fisiológicas e bioquímicas em sementes de feijão envelhecidas artificialmente Revista Brasileira de Sementes, v.26, n.1, p.110-119, 2004.

SAVANT, N.K.; KORNDORFER, G.H.; DATNOFF, L.E.; SNYDER, G.H. Silicon nutricion and sugarcane production: A Review. Journal of Plant Nutrition, v.22, n.12, p.1853-1903, 1997.

SHATTERS, R.G.; ABDELGHANY, A.; ELBAGOURY, O.; WEST, S.H. Soybean seed deterioration and response to osmotic priming: changes in specific enzyme activities in extracts from dry and germinationy seeds. Seed Science Research, v.4, n.1, p.33-41, 1994.

VIEIRA, A.R.; FRAGA, A.C.; VIEIRA, M.G.G.C.; SOARES, A.A.; OLIVEIRA, J.A. Dormência e qualidade fisiológica de sementes de arroz armazenadas em diferentes regiões do estado de Minas Gerais. Ciência e Agrotecnologia, v.26, n.1, p.33-44, 2002.

WINSLOW, M.D. Silicon disease resistance and yield of rice genotypes under upland cultural conditions. Crop Science, v.32, p.1208-1213, 1992. 